\title{
The global burden attributable to low bone mineral density
}

\author{
L Sànchez-Riera, ${ }^{1,2}$ E Carnahan, ${ }^{3} \mathrm{~T} \mathrm{Vos}_{1}{ }^{3} \mathrm{~L}$ Veerman, ${ }^{4} \mathrm{R}$ Norman, ${ }^{4,5} \mathrm{~S} \mathrm{~S} \mathrm{Lim,}{ }^{3}$ \\ D Hoy, ${ }_{1}^{4}$ E Smith, ${ }^{1} \mathrm{~N}$ Wilson, ${ }^{1} \mathrm{~J}$ M Nolla, ${ }^{2}$ J S Chen, ${ }^{1}$ M Macara, ${ }^{1} \mathrm{~N}$ Kamalaraj, ${ }_{1}^{6} \mathrm{Y} \mathrm{Li},{ }^{7}$ \\ C Kok, ${ }^{1}$ C Santos-Hernández, ${ }^{8}$ L March $^{1}$
}

\begin{abstract}
Handling editor Tore K Kvien
- Additional material is published online. To view please visit the journal (http:// dx.doi.org/10.1136/ annrheumdis-2013-204320).
\end{abstract}

For numbered affiliations see end of article.

\section{Correspondence to} Dr Lídia Sànchez-Riera, Institut d'Investigació Biomèdica de Bellvitge, Hospital Universitari de Bellvitge, Department Reumatologia, Feixa Llarga s/n, L'Hospitalet de Llobregat, Barcelona 08907, Spain; 37416lsr@comb.cat

Received 28 July 2013 Revised 8 February 2014 Accepted 1 March 2014 Published Online First 1 April 2014

- http://dx.doi.org/10.1136/ annrheumdis-2013-204344

- http://dx.doi.org/10.1136/ annrheumdis-2013-204627

- http://dx.doi.org/10.1136/ annrheumdis-2013-204631

- http://dx.doi.org/10.1136/ annrheumdis-2013-204647

- http://dx.doi.org/10.1136/ annrheumdis-2013-204680

- http://dx.doi.org/10.1136/ annrheumdis-2013-204763

- http://dx.doi.org/10.1136/ annrheumdis-2014-205393

- http://dx.doi.org/10.1136/ annrheumdis-2014-205327

To cite: Sànchez-Riera L, Carnahan E, Vos T, et al. Ann Rheum Dis 2014;73:1635-1645.

\section{ABSTRACT}

Introduction The Global Burden of Disease Study 2010 estimated the worldwide health burden of 291 diseases and injuries and 67 risk factors by calculating disability-adjusted life years (DALYs). Osteoporosis was not considered as a disease, and bone mineral density (BMD) was analysed as a risk factor for fractures, which formed part of the health burden due to falls.

Objectives To calculate (1) the global distribution of BMD, (2) its population attributable fraction (PAF) for fractures and subsequently for falls, and (3) the number of DALYs due to BMD.

Methods A systematic review was performed seeking population-based studies in which BMD was measured by dual-energy $\mathrm{X}$-ray absorptiometry at the femoral neck in people aged 50 years and over. Age- and sex-specific mean \pm SD BMD values $\left(\mathrm{g} / \mathrm{cm}^{2}\right)$ were extracted from eligible studies. Comparative risk assessment methodology was used to calculate PAFs of BMD for fractures. The theoretical minimum risk exposure distribution was estimated as the age- and sex-specific 90th centile from the Third National Health and Nutrition Examination Survey (NHANES III). Relative risks of fractures were obtained from a previous metaanalysis. Hospital data were used to calculate the fraction of the health burden of falls that was due to fractures.

Results Global deaths and DALYs attributable to low BMD increased from 103000 and 3125000 in 1990 to 188000 and 5216000 in 2010, respectively. The percentage of low BMD in the total global burden almost doubled from 1990 (0.12\%) to 2010 (0.21\%). Around one-third of falls-related deaths were attributable to low BMD.

Conclusions Low BMD is responsible for a growing global health burden, only partially representative of the real burden of osteoporosis.

\section{INTRODUCTION}

Osteoporosis is a skeletal disorder characterised by compromised bone strength predisposing to an increased risk of bone fractures. ${ }^{1}$ Osteoporotic fractures are defined as those occurring as the result of a low-impact trauma, with consequences ranging from chronic pain to institutionalisation and death. ${ }^{2-8}$ For people over 50 years of age living in a developed country, the lifetime risk of sustaining any fracture is $\sim 50 \%$ for women and $20 \%$ for men. ${ }^{9}$ Bone strength primarily reflects the integration of bone mineral density (BMD) and bone quality. The latter is awkward to assess on a population basis, while BMD is a well-defined predictor of fracture risk ${ }^{10} 11$ and is easily measurable. For a clinical approach, osteoporosis is defined by a threshold of 2.5 SDs below the mean BMD value of the young reference. ${ }^{12} 13$ However, the risk of fracture due to reduced BMD is gradual over a continuum.

This paper follows the comparative risk assessment (CRA) methodology in the Global Burden of Disease (GBD) Study 2010. ${ }^{14}$ The two primary outcome measures for the GBD work are deaths and disability-adjusted life years (DALYs), which combine the years lived with disability (YLDs) and the years lost due to premature mortality (years of life lost due to premature mortality (YLLs)). ${ }^{15}$ Burden estimates were made for 291 diseases and injuries. ${ }^{15}$ The burden arising from 67 risk factors was estimated by determining population attributable fractions (PAFs). ${ }^{14}$ Osteoporosis per se was not considered as a disease, and, for the first time, BMD was included in the global burden estimates as a risk factor for fractures, which represented a proportion of the global burden from falls. We summarise the methods used to calculate the contribution of low BMD to the burden of fractures due to falls and present estimates by age and sex by world region. We also document trends in attributable burden between 1990 and 2010. Estimates of burden were limited to populations aged 50 years and older, as osteoporotic fractures represent little burden at younger ages in the general population.

This report is part of the Musculoskeletal Expert Group series within the GBD 2010 Initiative. ${ }^{14-18}$ Extended reports on the overall methods, ${ }^{19}$ global burden of osteoarthritis, ${ }^{20}$ rheumatoid arthritis, ${ }^{21}$ gout, ${ }^{22}$ low back pain, ${ }^{23}$ neck pain, ${ }^{24}$ occupationally related low back pain, ${ }^{25}$ other musculoskeletal conditions $^{26}$ and final conclusions ${ }^{27}$ have also been published.

\section{METHODS}

\section{Definition of the exposure variable}

We performed a systematic review of Medline, Embase, CAB Abstracts, CINAHL, WHOLIS and SIGLE databases for population-based studies published from 1980 to 2010 with BMD values in $\mathrm{g} / \mathrm{cm}^{2}$ measured by dual-energy X-ray absorptiometry (DXA) at the femoral neck (FN). In regions with limited data, we also included other types of study (eg, non-population-based) as long as the sample was considered to be representative of the 


\section{Clinical and epidemiological research}

Figure 1 Summary for the Systematic Review for Low Bone Mineral Density as a Risk Factor. (A) Flowchart for the systematic review process. Exclusion criteria: A, subsample not representative of the population (ie, athletes); $B$, non-population-based studies (ie,clinical-based); C, no prevalence/incidence data; $D$, only subtypes of osteoporosis assessed (ie, steroid-induced osteoporosis); $E_{\text {, }}$ sample number $<150 ; F$, reviews. Final list of manuscripts used for BMD as the exposure variable can be found in Appendix 1, supplementary online file. (B) Search strategies for the systematic review. Search strategies are shown for BMD as the exposure variable (search strategy 1) and BMD as a risk factor for fractures (search strategy 2). *The whole list of the world countries was used as Subject Headings (SH) in Medline, Embase, CINAHL and CAB abstracts. GBD, global burden of disease; BMD, bone mineral density.

A

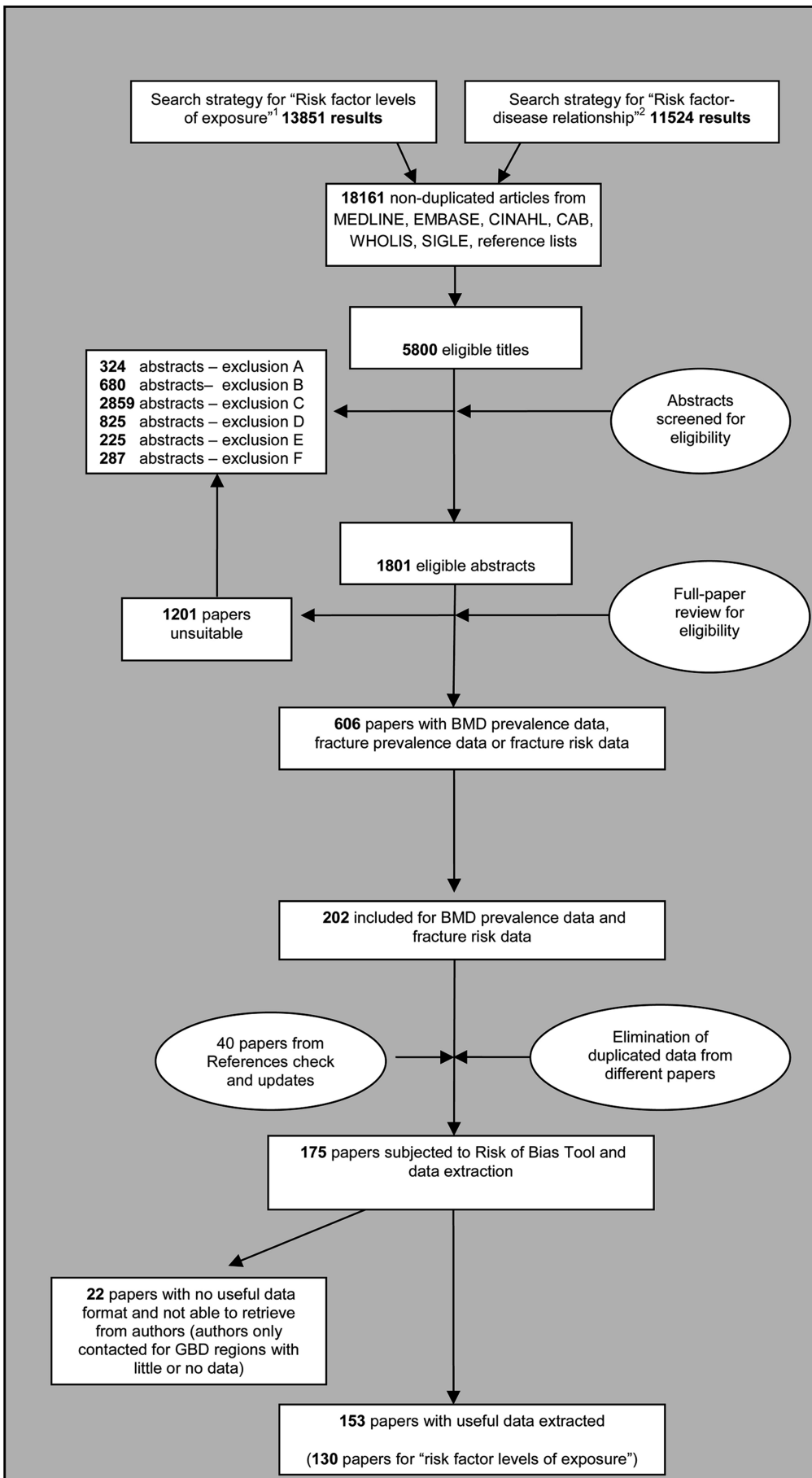

B

1. Search strategy for "Risk factor levels of exposure"

(osteoporosis OR osteopenia OR osteopaenia OR bone mineral density OR radiolucency)

AND

(prevalen* OR inciden* OR cross-sectional OR cross sectional OR epidemiol* OR survey OR populationbased $O R$ population based OR population study $O R$ population sample OR cohort OR follow-up OR follow up OR longitudinal OR regist* OR data collection)

AND

2. Search strategy for "Risk factor-disease
relationship"
(osteoporosis OR osteopenia OR osteopaenia OR bone
mineral density OR radiolucency)
AND
(fracture* OR risk)
AND
(GBD Countries SH)*




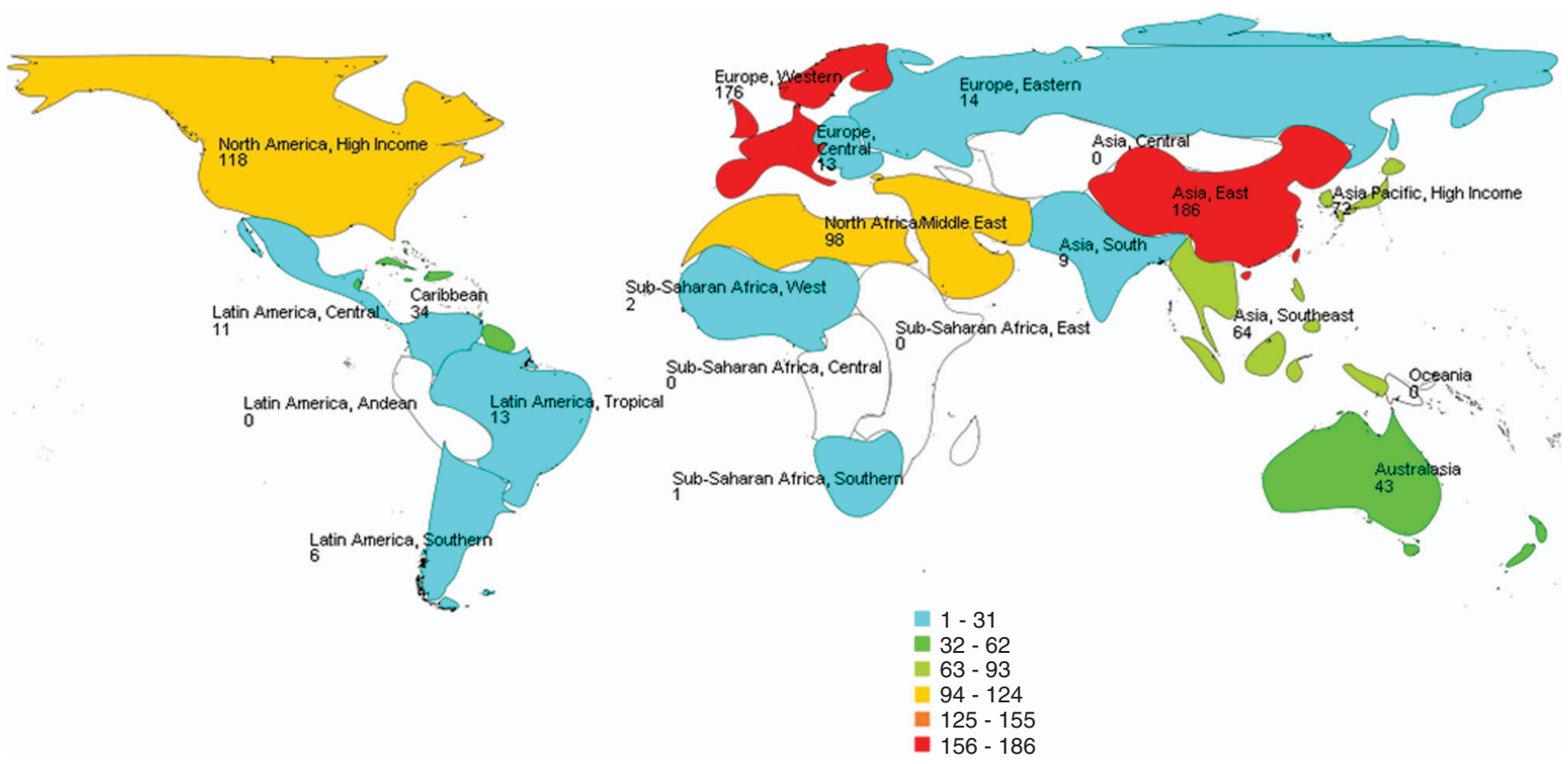

Figure 2 Number of data points of mean bone mineral density at the femoral neck measured by dual-X-ray absorptiometry by each of the 21 GBD world regions. All years (1980-2010), all ages, both sexes. Regions in white have no data. GBD, global burden of disease.

national population. Central DXA is the most validated technique for measuring BMD. ${ }^{12} 13$ The location at the FN is justified by the evidence that the morbidity and mortality related to hip fracture (the osteoporotic outcome with the highest burden) is better predicted when BMD is measured at the FN rather than the spine or forearm. ${ }^{11}$ Furthermore, measurement at the FN has been found to correlate well with vertebral and other osteoporotic fractures. ${ }^{11}$

\section{Data extraction and processing}

A database was developed and implemented in MS Excel, and information was extracted from included studies into the following predetermined fields for the exposure variable: region, country, year of publication, study type, study sample size, population description, coverage, urbanicity (rural, urban or both), start year of data collection, last year of data collection, age group start, age group end, sex, ethnicity, DXA manufacturer, DXA FN-specific coefficient of variation, and mean BMD value in $\mathrm{g} / \mathrm{cm}^{2}$ and SD.

All mean BMD and SD values with different DXA manufacturers (mainly Hologic, Norland and Lunar) were standardised using an international conversion formula ${ }^{28}$ to standardise mean BMD (sBMD) and SD (sSD).

Finally, a systematic data-cleaning process was performed to identify double-counted data and inconsistencies in the values.

Search strategies and results of the systematic review for the exposure variable are shown in figures $1 \mathrm{~A}, \mathrm{~B}$ and 2 , respectively.

\section{Modelling strategy}

Eligible articles were assessed for bias using a modified version of a validated Risk of Bias (RoB) tool ${ }^{29}$ developed for prevalence studies and adapted for osteoporosis. ${ }^{30}$ For selection bias, the risk was considered low when most recruited subjects were included, moderate when only healthy subjects were included, and high when subjects with prior fractures were excluded. The RoB tool was not found to have significant predictive value, ${ }^{30}$ and, consequently, all studies after the data-cleaning process were included.
As data were available for only selected country-time periods, the mean sBMD and SSD was estimated separately for all countrytime periods using DisMod-MR, a Bayesian meta-regression tool developed specifically for GBD 2010. ${ }^{17}$ The model included fixed effects for study-specific covariates, and random effects by GBD super-region, region and country. Study-specific covariates accounted for inconsistencies in the raw data-for example, data that were subnational (rather than nationally representative), or data that were collected in a non-gold-standard way (eg, nonpopulation based). National-level covariates can be used in the model to inform the global and country-level trends, and are not study-specific; lag-distributed income per capita, mean body mass index, and availability of milk based on the Food and Agriculture Organization of the United Nations disappearance data (imports plus local production minus exports) were tested. None of these demonstrated a significant improvement in the predictive ability of the model and were therefore not included.

\section{RELATIVE RISK ASSESSMENT: PAF OF LOW BMD TO FRACTURES}

\section{Effect size estimates}

The estimates of relative risk (RR) for fractures were based on a meta-analysis of 12 population-based studies from Western Europe, USA, Canada, Japan and Australia published in 2005. ${ }^{11}$ This study reported age- and sex-adjusted RRs for hip and non-hip fractures attributable to BMD. Our systematic review process also included searches for longitudinal population-based studies with data on RR of fracture related to FN BMD (figure 1). Data were heterogeneous in terms of BMD location measurement, fracture outcome and study design. Only eight relevant prospective studies ${ }^{31-38}$ published since 2005 were found, with RR estimates similar to those published in the previous meta-analysis. ${ }^{11}$

The estimates of the gradient of risk (RR/SD) for BMD Z-scores, based on the combined data for men and women, were obtained from the authors of the meta-analysis. ${ }^{11}$ The Z-score was established within each study population separately, which made the RRs dependent on the spread within the study 
population. For our purposes this was undesirable, and therefore the 'relative' RR/SD values were converted into 'absolute' RR/ $0.1 \mathrm{~g} / \mathrm{cm}^{2}$ values (table 1) using a weighted average of the spread in BMD values for the populations that were represented in the meta-analysis, as they were estimated in the DisMod-MR output, and so derived risk estimates for men and women separately by 5 -year age group.

\section{Theoretical minimum risk exposure distribution and calculation of PAF}

Comparative risk assessment (CRA) methodology ${ }^{14} 39$ was used to estimate the proportion of fractures that are attributable to age- and sex-specific levels of BMD analysed as a continuous variable. CRA estimates are based on a counterfactual exposure distribution that would result in the lowest population risk that is theoretically possible, referred to as the theoretical minimum risk exposure distribution (TMRED). ${ }^{40}$ The sex- and agespecific 90th percentile from the Third National Health and Nutrition Examination Survey (NHANES III), ${ }^{41}$ the most broadly accepted standard international reference, ${ }^{13}$ was chosen as the TMRED (table 2). The SD of the TMRED was estimated on the basis of the relationship between means and SDs from a regression of all studies in the final dataset that measured means and SDs of BMD.

Using the exposure distributions and the RR for fracture by BMD level defined above, PAFs were calculated ${ }^{42}$ for hip fractures, non-hip vertebra fractures (fractures of vertebra occurring without hip fracture) and non-hip fractures, using the following formula:

$$
P A F=\frac{\int_{x=0}^{m} R R(x) P(x) d x-\int_{x=0}^{m} R R(x) P^{\prime}(x) d x}{\int_{x=0}^{m} R R(x) P(x) d x}
$$

where $R R(x)$ is the $R R$ at exposure level $x, P(x)$ is the population distribution of exposure, $\mathrm{P}^{\prime}(\mathrm{x})$ is the counterfactual distribution of exposure, and $\mathrm{m}$ the maximum exposure level.

Table 1 Relative risk (RR) of hip and non-hip fractures for each $0.1 \mathrm{~g} / \mathrm{cm}^{2}$ decrease in bone mineral density (BMD)

\begin{tabular}{|c|c|c|c|c|c|c|}
\hline \multirow[b]{3}{*}{ Age (years) } & \multicolumn{6}{|c|}{ RR/0.1 BMD unit decrease } \\
\hline & \multicolumn{3}{|c|}{ Non-hip fractures } & \multicolumn{3}{|c|}{ Hip fractures } \\
\hline & Mean & $\mathrm{LCl}$ & $\mathrm{HCl}$ & Mean & $\mathrm{LCl}$ & $\mathrm{HCl}$ \\
\hline \multicolumn{7}{|l|}{ Men } \\
\hline $50-54$ & 1.152 & 1.058 & 1.254 & 2.603 & 2.042 & 3.319 \\
\hline $55-59$ & 1.183 & 1.104 & 1.268 & 2.421 & 1.978 & 2.961 \\
\hline $60-64$ & 1.215 & 1.147 & 1.286 & 2.282 & 1.938 & 2.689 \\
\hline $65-69$ & 1.249 & 1.189 & 1.311 & 2.177 & 1.914 & 2.478 \\
\hline $70-74$ & 1.297 & 1.238 & 1.357 & 2.100 & 1.897 & 2.324 \\
\hline $75-79$ & 1.338 & 1.279 & 1.402 & 1.921 & 1.781 & 2.072 \\
\hline $80+$ & 1.371 & 1.302 & 1.444 & 1.730 & 1.627 & 1.840 \\
\hline \multicolumn{7}{|l|}{ Women } \\
\hline $50-54$ & 1.158 & 1.061 & 1.265 & 2.697 & 2.096 & 3.470 \\
\hline $55-59$ & 1.201 & 1.114 & 1.296 & 2.629 & 2.109 & 3.278 \\
\hline $60-64$ & 1.237 & 1.162 & 1.317 & 2.466 & 2.062 & 2.951 \\
\hline $65-69$ & 1.286 & 1.216 & 1.358 & 2.412 & 2.084 & 2.792 \\
\hline $70-74$ & 1.342 & 1.274 & 1.413 & 2.315 & 2.064 & 2.596 \\
\hline $75-79$ & 1.398 & 1.327 & 1.475 & 2.118 & 1.942 & 2.311 \\
\hline $80+$ & 1.438 & 1.355 & 1.526 & 1.878 & 1.750 & 2.016 \\
\hline
\end{tabular}

Values are RR of fracture per each 0.1 unit of BMD decrease. Units of BMD are $\mathrm{g} / \mathrm{cm}^{2}$. Adapted from Johnell et al. ${ }^{11}$

$\mathrm{LCl}$, lower $95 \% \mathrm{Cl} ; \mathrm{HCl}$, high $95 \% \mathrm{Cl}$.
Table 2 Theoretical-minimum-risk exposure distribution (TMRED) for men and women aged 50 years and over

\begin{tabular}{lll}
\hline Age & Mean sBMD & SD \\
\hline Women & & \\
$50-59$ & 1.00 & 0.14 \\
$60-69$ & 0.92 & 0.14 \\
$70-79$ & 0.84 & 0.13 \\
$80+$ & 0.78 & 0.13 \\
Men & & \\
$50-59$ & 1.09 & 0.16 \\
$60-69$ & 1.06 & 0.16 \\
$70-79$ & 1.02 & 0.16 \\
$80+$ & 0.98 & 0.16
\end{tabular}

Values are expressed in $\mathrm{g} / \mathrm{cm}^{2}$ and correspond to the age- and sex-specific 90th centile of the mean BMD from NHANES $\mathrm{III}^{41}$ after internationally recognised standardisation. ${ }^{28}$

sBMD, standardised bone mineral density.

\section{HEALTH BURDEN OF FRACTURES AS A FRACTION OF FALLS}

For attributing deaths to low BMD, the difficulty is that deaths are categorised according to cause of injury (ie, falls), not nature of injury (ie, fracture), and low BMD or osteoporosis is not coded as a cause. Fractures can be found as a consequence of many events such as road accident, assault or natural disasters. For the purposes of this analysis, estimates were restricted to fractures due to falls, where we expected most osteoporotic fractures to be coded. It was necessary to turn to hospital data from Brazil, ${ }^{43}$ Canada, ${ }^{44}$ Mexico ${ }^{45}$ and the USA $^{46}{ }^{47}$ to estimate the fraction of in-hospital deaths from falls that involved hip and vertebra fractures. Those with a mention of concurrent head or internal injury were excluded. Other fracture types were also excluded, as these were considered less likely to lead to death, as supported by an analysis of the Australian mortality database. ${ }^{48}$ Among those inpatient deaths where the primary cause for admission was a fall, a large fraction, especially at older ages, involved a hip fracture; only a small proportion of deaths associated with a vertebral fracture were not also associated with a hip fracture (table 3). As this was the only data source used to determine the fraction of deaths from falls due to hip fracture or vertebra fracture, it was necessary to apply these age- and sex-specific proportions to falls to every country.

Disability from falls is estimated by the nature of the associated injury, and therefore the short- and long-term disability was estimated for fractures by site. The RRs for hip fracture

Table 3 Fraction of in-hospital deaths from falls involving hip and vertebra fractures

\begin{tabular}{llll}
\hline Sex & Age & Hip fracture (\%) & Non-hip vertebra fracture (\%) \\
\hline \multirow{2}{*}{ Women } & $50-59$ & 61.6 & 2.6 \\
& $60-69$ & 73.2 & 1 \\
& $70-79$ & 79.4 & 0.6 \\
\multirow{4}{*}{ Men } & $80+$ & 82.5 & 0.5 \\
& $50-59$ & 46 & 8 \\
& $60-69$ & 67.5 & 4.6 \\
& $70-79$ & 79.8 & 0.9 \\
& $80+$ & 84.2 & 0.4
\end{tabular}

Percentages express the fraction of in-hospital deaths from falls that involve hip fractures and non-hip vertebra fractures (deaths from vertebral fractures that occur without hip fracture). Calculated with in-patient hospital data from Brazil, ${ }^{43}$ Canada, $^{44}$ Mexico ${ }^{45}$ and the USA. ${ }^{46} 47$ 
Mean Bone Mineral Density in g/cm2 at Femoral Neck by Country, Males 1990
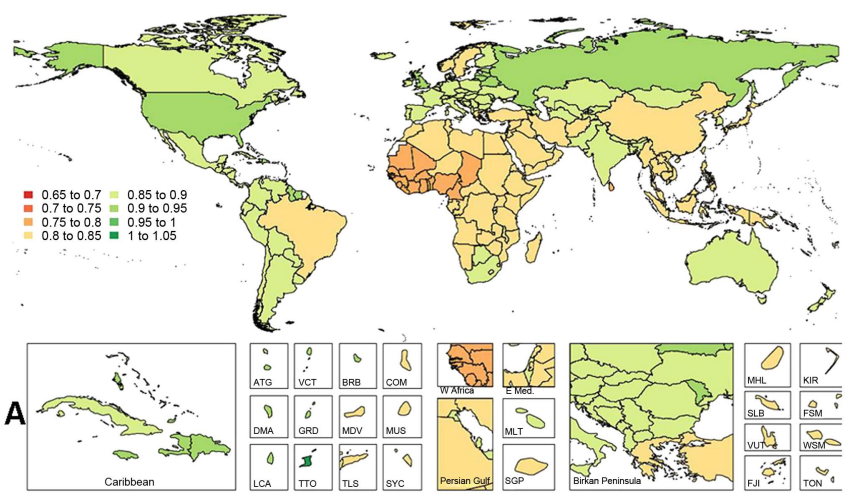

Mean Bone Mineral Density in g/cm2 at Femoral Neck by Country, Males 2010
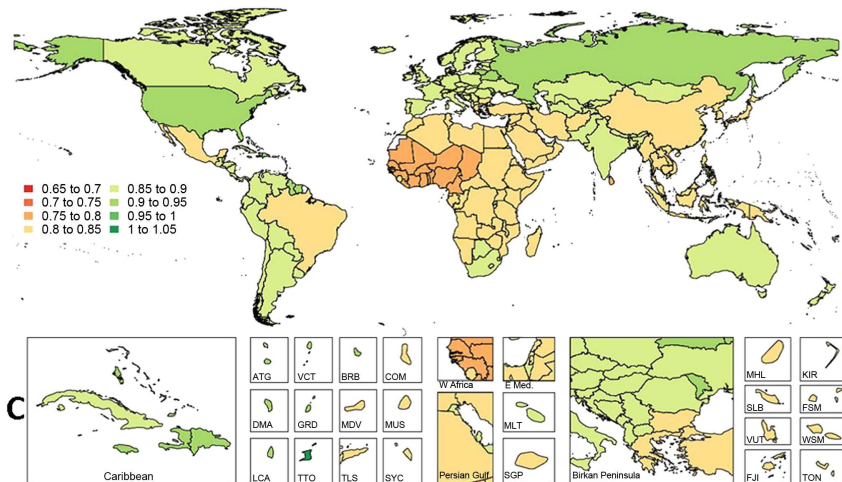

(1.

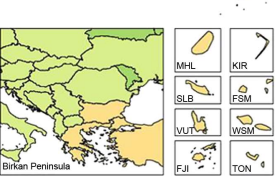

Mean Bone Mineral Density in g/cm2 at Femoral Neck by Country, Females 1990
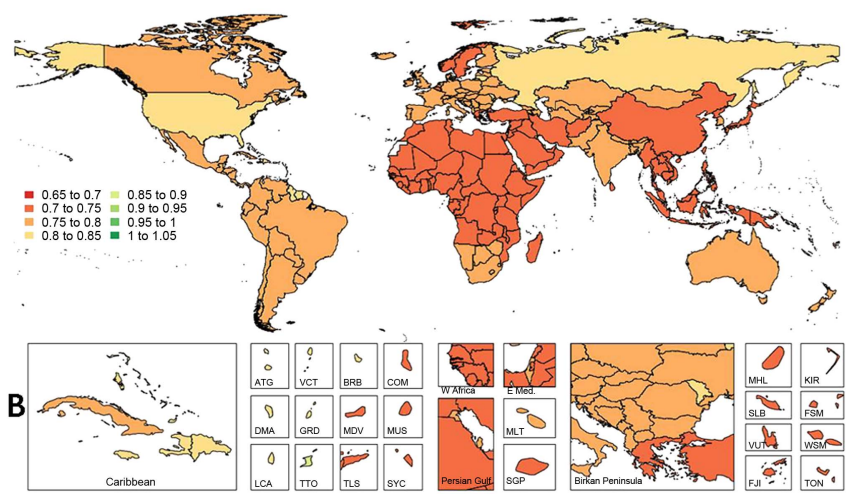

Mean Bone Mineral Density in $\mathrm{g} / \mathrm{cm} 2$ at Femoral Neck by Country, Females 2010
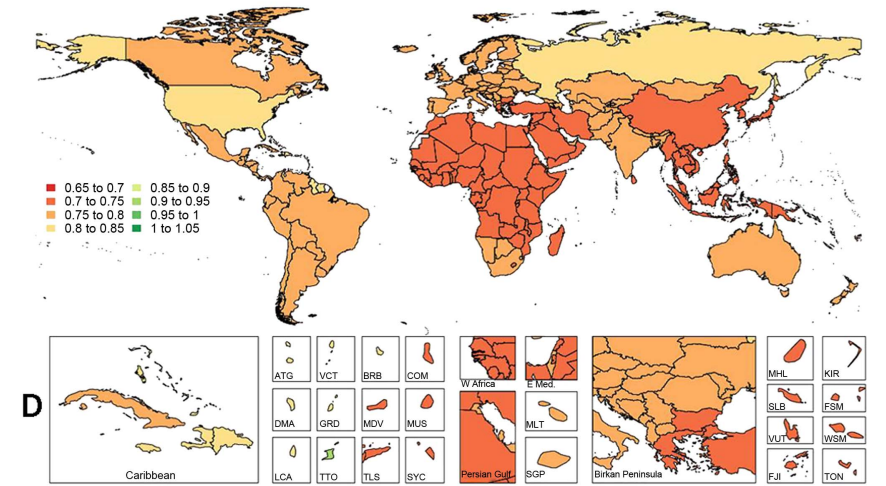

Figure 3 Word distribution of standardised bone mineral density in $\mathrm{g} / \mathrm{cm}^{2}$ at the femoral neck at country level. (A) Men, 1990; (B) women, 1990; (C) men, 2010; (D) women, 2010.

(table 1) were applied to the YLD estimates for hip fracture due to falls sub-cause. The RRs for non-hip fracture (table 1) were applied to YLD estimates for all other fracture sites known to be associated with osteoporosis (clavicle, scapula, humerus, skull, sternum, rib, face bone, radius or ulna, femur, patella, tibia, fibula, ankle, pelvis, vertebral, other extremities). Details on the disability weights for fracture types and methods used to calculate YLDs due to falls can be found elsewhere. ${ }^{17} 18$

\section{RESULTS}

There were 130 eligible articles (Appendix 1, supplementary online file), with a total of 860 data points from 49 countries and 17 world regions (figure 2). Worldwide distributions of mean BMD for people aged 50 years and over for 1990 and 2010 are shown in figure 3. Asia and Africa were the world regions with the lowest values of $\mathrm{BMD}$ at the $\mathrm{FN}$, while highincome North America, Caribbean and Eastern Europe showed the highest BMD values for both men and women. Although age-adjusted data showed an improving trend for BMD values over time, ${ }^{49}$ especially in Asia and Western Europe, BMD at a population level decreased in some regions as a result of the ageing of the population.

For all diseases, injuries and risk factors, data on DALYs, YLDs, YLLs and deaths can be seen online by region, country, year,
DALYs per 100,000 population by Country, Both Sexes, 1990
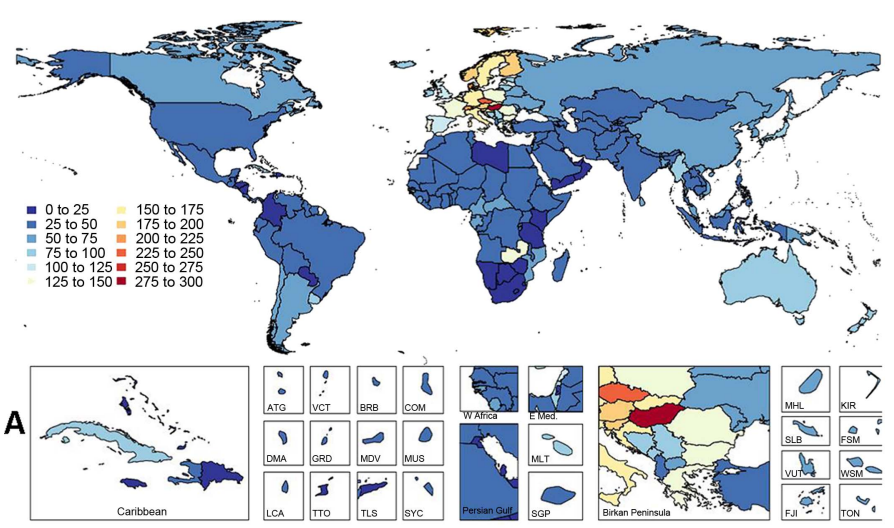

DALYs per 100,000 population by Country, Both Sexes, 2010
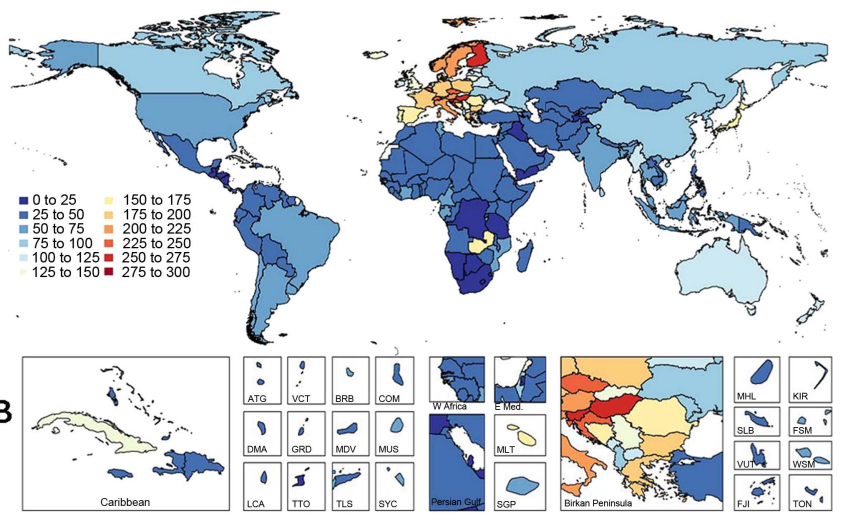

Figure 4 World distribution of disability-adjusted life years (DALYs) for low bone mineral density per 100000 population at country level. All ages, both sexes. (A) Estimations for 1990; (B) estimations for 2010 (for all estimations for 1990, 2005 and 2010 for men and women at country, region and super-region levels, please visit http://www.healthmetricsandevaluation.org/gbd/visualizations/country). 


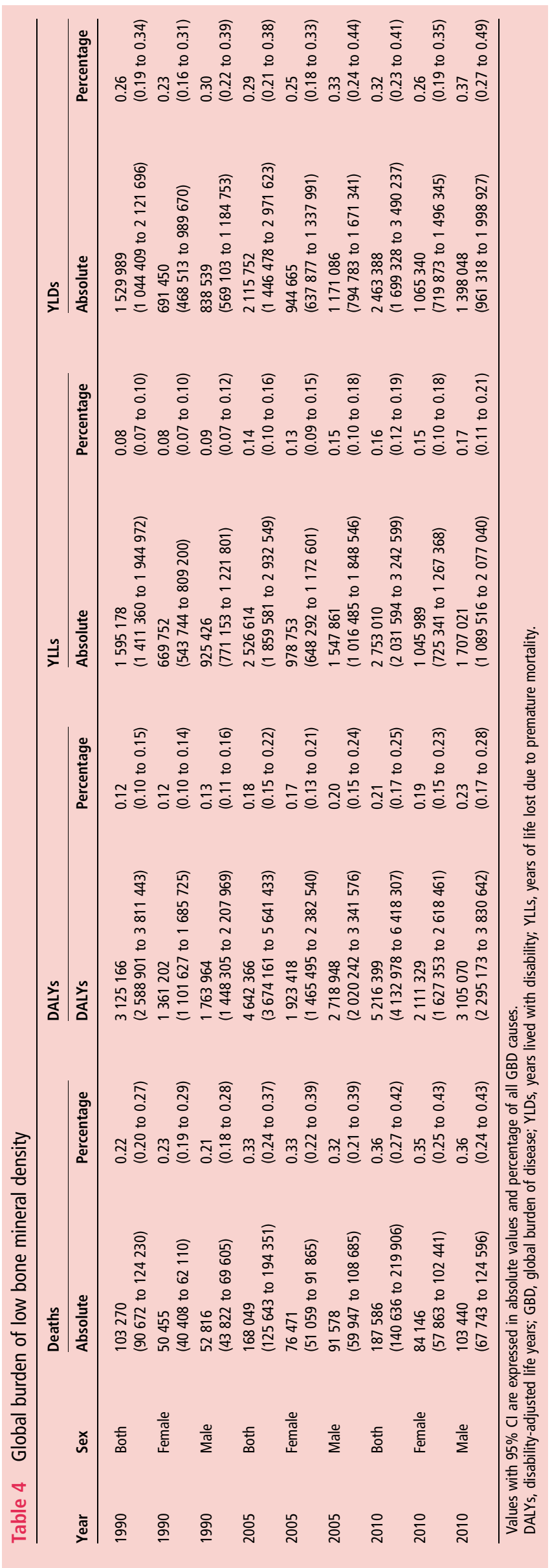

age and sex (http://www.healthmetricsandevaluation.org/gbd/ visualizations/country). Global deaths and DALYs attributable to low BMD increased from 103000 and 3125000 in 1990 to 188000 and 5216000 in 2010, respectively (table 4). The percentage of low BMD in the total global burden almost doubled from $1990(0.12 \%)$ to $2010(0.21 \%)$ (table 4). The fraction of the total regional burden increased in all regions except the Caribbean and Oceania. Asia East and South were the major contributors to the increase in global burden of low BMD. Rates of global DALYs per 100000 population increased markedly from 1990 to 2010, but the increase was modest after age standardisation (table 5), which reflects population growth and ageing. Rates were higher in Western Europe, Central Europe and high-income Asia Pacific (figure 4 and table 5), while the highest age-standardised rates were more commonly found in developing regions such as Sub-Saharan Africa East and West, Oceania, Asia East and South (table 5).

The PAFs of BMD for falls were generally higher for women than men for both 1990 and 2010. In general, world regions with a low gross domestic product showed the highest PAFs (Asia East and South-East, North Africa-Middle East, Sub-Saharan Africa East and West), with the exception of Eastern Europe. However, big disparities in PAFs were observed among highincome countries, even within the same world region-for example, Scandinavian countries compared with UK (figure 5).

In 1990, global DALYs and deaths attributable to low BMD constituted $12.1 \%$ and $29.6 \%$ of all falls-related DALYs and deaths, respectively. These percentages increased slightly to $14.8 \%$ and $34.7 \%$ for 2010 estimates. Table 6 shows percentages of the falls burden due to low BMD by world region.

Low BMD ranked low in terms of attributable DALYs compared with most risk factors, such as dietary factors, high blood pressure, smoking, alcohol use, high fasting plasma glucose, high body mass index, high cholesterol and low physical activity (http://www.healthmetricsandevaluation.org/gbd/visualizations/ gbd-heatmap). Globally, low BMD ranked 23rd among 25 risk factor categories for 2010 (dietary risk factors clustered into one category and occupational risk factors clustered into one category). By region, the highest ranks for low BMD were observed in Western Europe and high-income Asia Pacific, ranked 12th and 13th, respectively, followed by Central Europe, Australasia and high-income North America at 15th and Asia East at 16th.

\section{DISCUSSION}

Although age-adjusted data showed an improving trend of the global BMD values over time, the absolute burden of low BMD increased from 1990 to 2010, probably related to the global growth of the aged population. Higher age-standardised rates of DALYs and higher PAFs in developing regions probably reflect the importance of the potentially modifiable determinants of low BMD (such as nutritional factors and access to healthcare). Low BMD could be responsible for at least one-third of deaths attributable to falls, which is third in the list of major health burdens after road injuries and self-harm, as reported previously. ${ }^{15}$ However, the contribution of low BMD to the global health burden compared with other risk factors was low, and it is likely that the burden of osteoporosis has been underestimated for several reasons.

First, the choice of an age- and sex-specific TMRED masked the important role of age and sex in fracture risk, ${ }^{50}$ and it may explain in part the lower health burden of BMD compared with other risk factors. Given that the gradient of risk of fracture for each unit of BMD decrease is the same in men and women, ${ }^{11}$ the use of the young female reference seems reasonable in clinical settings. In the GBD framework, however, risk factor 
Downloaded from http://ard.bmj.com/ on December 1, 2016 - Published by group.bmj.com

Clinical and epidemiological research

Table 5 Rates of DALYs per 100000 population by GBD region in 1990 and 2010

\begin{tabular}{|c|c|c|c|c|c|c|c|c|}
\hline \multirow{3}{*}{$\begin{array}{l}\text { Location } \\
\text { Asia Pacific, high-income }\end{array}$} & \multicolumn{4}{|l|}{1990} & \multicolumn{4}{|l|}{2010} \\
\hline & \multicolumn{2}{|l|}{ All ages } & \multicolumn{2}{|c|}{ Age-standardised } & \multicolumn{2}{|l|}{ All ages } & \multicolumn{2}{|c|}{ Age-standardised } \\
\hline & 80.79 & (59.46 to 106.37 ) & 65.85 & (48.44 to 86.62 ) & 138.31 & (102.67 to 181.06$)$ & 63.43 & (47.48 to 82.93 ) \\
\hline Asia, Central & 38.02 & (26.64 to 50.90 ) & 54.17 & (37.79 to 72.72 ) & 37.46 & (26.80 to 52.41 ) & 49.41 & (35.15 to 69.01 ) \\
\hline Asia, East & 68.64 & (56.02 to 84.10 ) & 94.54 & (77.36 to 116.21 ) & 92.00 & (72.58 to 113.50$)$ & 86.45 & (68.28 to 106.73$)$ \\
\hline Asia, South & 44.15 & (32.85 to 59.10 ) & 86.92 & (65.52 to 115.84$)$ & 64.87 & (42.01 to 88.54 ) & 102.87 & (66.89 to 140.05$)$ \\
\hline Asia, Southeast & 45.39 & (35.50 to 55.66 ) & 85.71 & (66.39 to 104.44) & 62.48 & (46.36 to 77.96 ) & 84.81 & (62.64 to 105.55$)$ \\
\hline Australasia & 87.20 & (60.27 to 124.09$)$ & 69.28 & (48.18 to 98.00 ) & 117.27 & (79.24 to 164.28$)$ & 67.52 & (44.60 to 94.86 ) \\
\hline Caribbean & 48.02 & (35.73 to 60.13 ) & 66.22 & (49.20 to 83.01 ) & 62.56 & (46.94 to 79.73 ) & 66.16 & (49.74 to 84.60 ) \\
\hline Europe, Central & 154.51 & (121.21 to 192.20$)$ & 121.69 & (95.48 to 151.15 ) & 187.81 & (141.40 to 245.17 ) & 108.44 & (82.07 to 142.07 ) \\
\hline Europe, Eastern & 60.65 & (39.77 to 86.20 ) & 45.32 & (29.78 to 64.35$)$ & 85.59 & (54.13 to 118.30$)$ & 54.61 & (34.90 to 75.23 ) \\
\hline Europe, Western & 140.64 & (108.32 to 181.16$)$ & 83.04 & (63.72 to 107.39) & 183.26 & (140.75 to 239.56$)$ & 85.86 & (65.50 to 112.71 ) \\
\hline Latin America, Andean & 35.06 & (25.74 to 45.51$)$ & 67.45 & (49.50 to 87.44$)$ & 36.57 & (27.09 to 48.39 ) & 50.41 & (37.37 to 66.73) \\
\hline Latin America, Central & 27.00 & (21.75 to 33.29 ) & 51.84 & (41.80 to 63.95$)$ & 35.65 & (28.15 to 43.87 ) & 47.45 & (37.43 to 58.41$)$ \\
\hline Latin America, Southern & 63.37 & (44.87 to 86.13 ) & 64.96 & (45.86 to 88.32 ) & 63.86 & (45.05 to 87.23 ) & 50.92 & (35.90 to 69.74 ) \\
\hline Latin America, Tropical & 29.45 & (21.24 to 39.82 ) & 52.47 & (37.74 to 70.95$)$ & 56.82 & (37.06 to 75.07) & 63.95 & (41.54 to 84.41$)$ \\
\hline North Africa/Middle East & 30.78 & (23.18 to 40.86 ) & 66.54 & (50.20 to 88.00$)$ & 37.45 & (27.85 to 49.71 ) & 60.63 & (45.36 to 80.72 ) \\
\hline North America, high-income & 43.48 & (28.23 to 59.15$)$ & 31.57 & (20.62 to 42.99 ) & 70.82 & (43.07 to 99.00 ) & 41.83 & (25.21 to 58.36$)$ \\
\hline Oceania & 56.02 & (39.92 to 76.49 ) & 147.40 & (106.54 to 199.03 ) & 41.21 & (30.75 to 55.27$)$ & 91.17 & (69.18 to 118.80$)$ \\
\hline Sub-Saharan Africa, Central & 30.92 & (23.39 to 39.60$)$ & 77.97 & (59.17 to 99.77 ) & 27.08 & (20.45 to 35.20$)$ & 73.34 & (55.58 to 95.12 ) \\
\hline Sub-Saharan Africa, Eastern & 37.20 & (29.19 to 48.64$)$ & 96.50 & (75.27 to 125.60$)$ & 42.24 & (28.34 to 53.42 ) & 103.90 & (69.87 to 131.93$)$ \\
\hline Sub-Saharan Africa, Southern & 15.51 & (10.70 to 21.08 ) & 36.91 & (25.43 to 50.07 ) & 22.20 & (15.40 to 30.10$)$ & 38.17 & (26.33 to 51.75$)$ \\
\hline Sub-Saharan Africa, Western & 46.15 & (37.28 to 56.03 ) & 114.76 & (92.56 to 138.91 ) & 44.07 & (36.03 to 52.63 ) & 108.31 & (87.83 to 130.19$)$ \\
\hline Global & 58.95 & (48.83 to 71.89 ) & 77.89 & (64.51 to 94.96$)$ & 75.71 & (59.99 to 93.15$)$ & 79.87 & (63.28 to 98.22 ) \\
\hline
\end{tabular}

A Mean Population Attributable Fraction for Falls by Country, Males $1990 \quad$ B Mean Population Attributable Fraction for Falls by Country, Females 1990
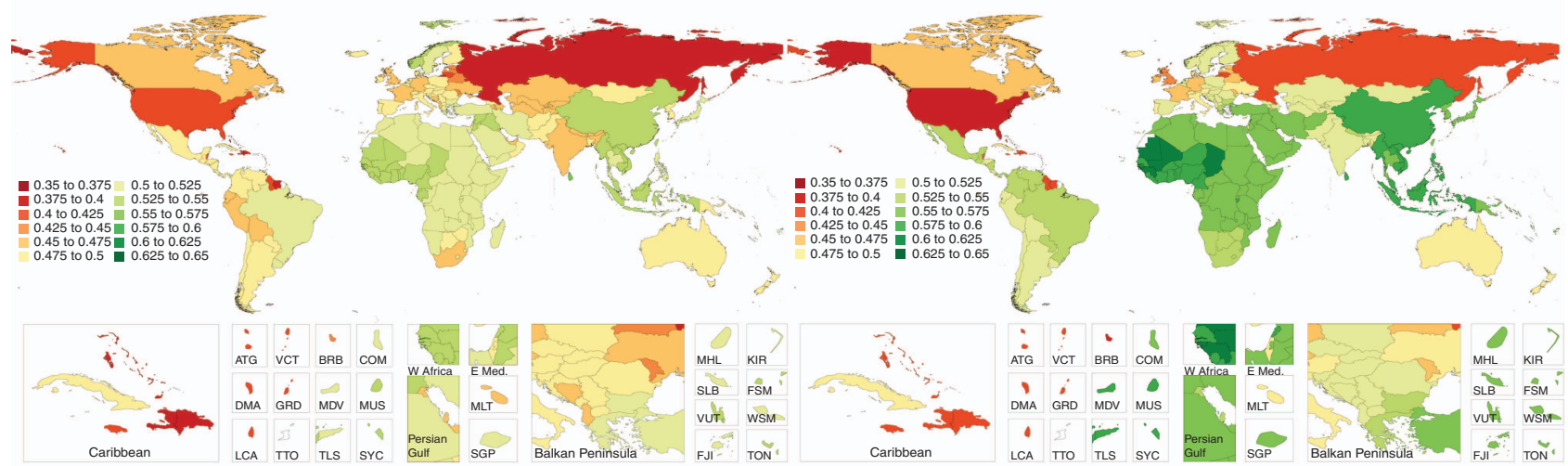

C Mean Population Attributable Fraction for Falls by Country, Males 2010 D Mean Population Attributable Fraction for Falls by Country, Females 2010
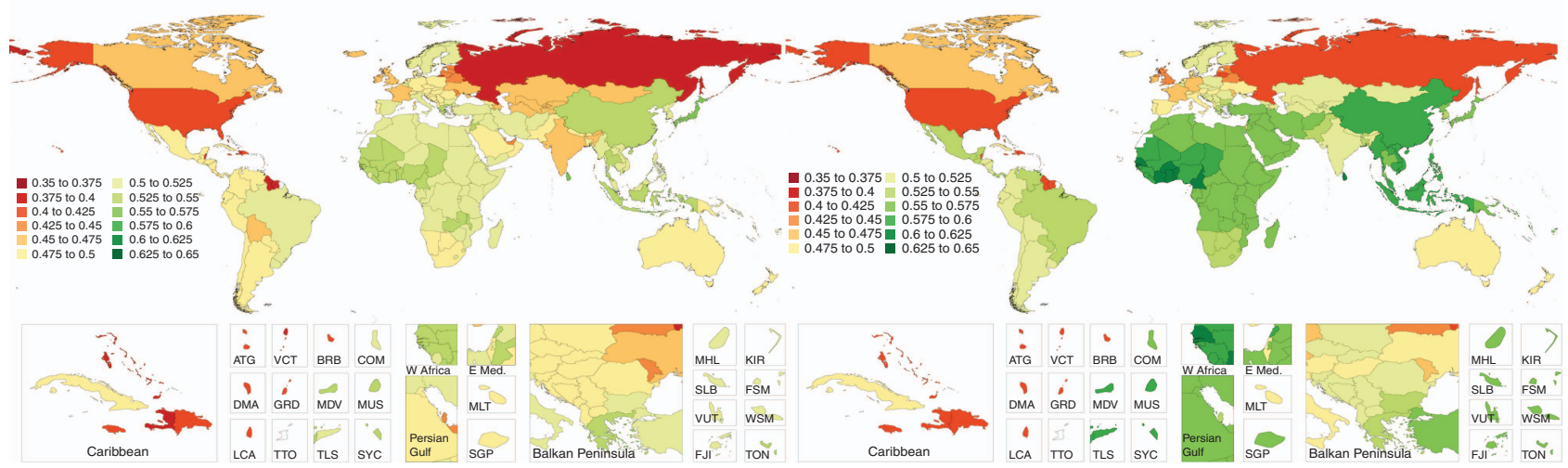

Figure 5 Age-standardized population attributable fraction (PAF) of low bone mineral density for falls. Values are expressed on 0-1 scale. (A) Men, 1990; (B) women, 1990; (C) men, 1990; (D) women, 2010. Age standardization was obtained using the global standard proposed by the WHO in 2001 (http://www.who.int/healthinfo/paper31.pdf). 
Table 6 Burden of low bone mineral density as a percentage of falls-related burden by GBD region and year

\begin{tabular}{|c|c|c|c|c|c|c|c|c|c|c|c|c|c|c|c|c|}
\hline \multirow{3}{*}{$\begin{array}{l}\text { Region } \\
\text { Asia Pacific, high income }\end{array}$} & \multicolumn{8}{|l|}{1990} & \multicolumn{8}{|l|}{2010} \\
\hline & \multicolumn{2}{|c|}{ DALYs } & \multicolumn{2}{|l|}{ YLLs } & \multicolumn{2}{|l|}{ YLDs } & \multicolumn{2}{|c|}{ Deaths } & \multicolumn{2}{|c|}{ DALYs } & \multicolumn{2}{|l|}{ YLLs } & \multicolumn{2}{|l|}{ YLDs } & \multicolumn{2}{|c|}{ Deaths } \\
\hline & 16.3 & (13.6 to 19.3 ) & 21.7 & (18.8 to 25.8$)$ & 14.4 & (11.4 to 17.6$)$ & 38.0 & (33.3 to 42.9 ) & 22.3 & (18.8 to 25.8$)$ & 38.2 & (32.1 to 42.6 ) & 18.1 & (14.7 to 21.5 ) & 50.5 & (44.3 to 55.6$)$ \\
\hline Asia, Central & 8.0 & (6.4 to 9.4 ) & 4.9 & (4.1 to 5.6 ) & 9.7 & (7.4 to 11.9 ) & 12.7 & (10.9 to 14.3 ) & 8.5 & (6.9 to 10.1 ) & 6.0 & (4.7 to 7.3 ) & 9.7 & (7.6 to 11.7 ) & 14.0 & (11.6 to 16.3 ) \\
\hline Asia, East & 13.7 & (11.6 to 15.6$)$ & 14.6 & (11.5 to 16.9$)$ & 12.7 & (10.4 to 15.0$)$ & 32.8 & (27.8 to 36.7 ) & 17.5 & (15.2 to 20.0$)$ & 21.8 & (18.6 to 25.7 ) & 14.1 & (11.7 to 16.7 ) & 39.7 & (35.4 to 44.6 ) \\
\hline Asia, South & 8.9 & (7.0 to 11.0$)$ & 9.1 & (7.0 to 11.5 ) & 8.7 & (6.2 to 11.1$)$ & 21.6 & (17.5 to 25.8$)$ & 11.9 & (9.0 to 14.8$)$ & 13.7 & (10.1 to 17.8$)$ & 9.2 & (6.7 to 11.7 ) & 28.3 & (21.8 to 34.4$)$ \\
\hline Asia, Southeast & 13.8 & (11.6 to 16.2$)$ & 17.7 & (14.0 to 21.6 ) & 10.5 & (8.7 to 12.4 ) & 35.3 & (30.3 to 40.8 ) & & (13.6 to 19.1$)$ & 23.2 & (19.3 to 26.8 ) & 11.3 & (9.3 to 13.3 ) & 0.1 & 4.9) \\
\hline Australasia & 15.0 & (11.1 to 18.7$)$ & 27.2 & (21.6 to 32.3 ) & 12.7 & (9.1 to 16.4 ) & 40.5 & (30.5 to 48.2 ) & 17.3 & (12.9 to 21.5$)$ & 35.2 & (27.3 to 41.6 ) & 14.3 & (10.3 to 18.2$)$ & 44.3 & (32.6 to 52.7 ) \\
\hline Caribbean & 13.6 & (10.7 to 16.3$)$ & 19.0 & (14.7 to 22.9 ) & 9.4 & (7.3 to 11.6 ) & 36.8 & ( 28.2 to 43.7 ) & 12.6 & (9.7 to 15.3 ) & 24.8 & (19.3 to 29.7 ) & 8.3 & (6.3 to 10.4 ) & 40.3 & (29.5 to 48.4 ) \\
\hline Europe, Central & 18.9 & (16.0 to 21.8$)$ & 26.4 & (23.2 to 29.4 ) & 14.6 & (12.0 to 17.5$)$ & 39.9 & (34.2 to 44.7 ) & 20.0 & (16.9 to 23.2 ) & 32.0 & (28.1 to 35.2 ) & 16.0 & (13.2 to 19.0$)$ & 43.1 & (37.1 to 47.8 ) \\
\hline Europe, Eastern & 11.1 & (7.7 to 14.4 ) & 13.8 & (9.6 to 17.3 ) & 9.7 & (6.4 to 13.0 ) & 24.0 & (16.9 to 29.9 ) & 2.7 & (8.7 to 16.0 ) & 16.1 & (11.0 to 20.2 ) & 0.3 & (6.7 to 13.6 ) & 25.9 & (17.9 to 32.3 ) \\
\hline Europe, Western & 18.5 & (15.8 to 21.3 ) & 30.9 & (27.0 to 34.8 ) & 14.4 & (12.1 to 16.6$)$ & 40.9 & (34.6 to 46.7 ) & 20.1 & (17.0 to 23.1$)$ & 36.8 & (32.5 to 40.6 ) & 16.1 & (13.4 to 19.1$)$ & 43.7 & (37.1 to 48.9 ) \\
\hline Latin America, Andean & 9.3 & (7.4 to 11.2 ) & 9.6 & (7.6 to 11.6 ) & 9.1 & (6.9 to 11.5 ) & 23.4 & (19.2 to 27.3 ) & 11.7 & (9.2 to 13.9 ) & 13.4 & (10.9 to 15.8 ) & 10.8 & $(8.0$ & 30.2 & $(24.8$ \\
\hline Latin America, Central & 11.0 & (9.5 to 12.5$)$ & 11.4 & (10.0 to 13.1$)$ & 10.5 & (8.4 to 12.6$)$ & 27.5 & (24.4 to 30.7 ) & 14.7 & (12.5 to 16.9$)$ & 18.7 & (15.5 to 21.2 ) & 11.5 & (9.4 to 13.6$)$ & 36.1 & (31.5 to 40.1 ) \\
\hline Latin America, Southern & 14.3 & (10.9 to 17.5$)$ & 20.1 & (16.2 to 23.8 ) & 12.1 & (8.6 to 15.6 ) & 37.3 & (29.8 to 43.1 ) & 15.3 & (12.0 to 18.7$)$ & 26.2 & (21.1 to 30.8 ) & 12.8 & (9.8 to 16.0$)$ & 42.0 & (33.1 to 49.0 ) \\
\hline Latin America, Tropical & 11.3 & (9.1 to 13.6 ) & 11.2 & (9.0 to 14.0 ) & 11.4 & (8.8 to 14.2 ) & 26.8 & (21.8 to 32.1 ) & 17.1 & (12.9 to 20.8 ) & 22.6 & (15.8 to 27.2 ) & 13.6 & (10.3 to 16.8$)$ & 40.0 & (31.7 to 46.9 ) \\
\hline North Africa/Middle East & 8.6 & (7.3 to 10.0 ) & 5.6 & (4.2 to 7.0 ) & 10.5 & (8.8 to 12.2 ) & 17.1 & (13.6 to 20.7 ) & 10.5 & (9.1 to 11.9 ) & 8.9 & (7.8 to 10.3 ) & 11.2 & (9.4 to 13.1 ) & 23.2 & (20.8 to 26.0 ) \\
\hline North America, high income & 13.5 & (9.4 to 17.4$)$ & 24.1 & (17.3 to 30.2$)$ & 8.7 & (5.7 to 11.6 ) & 34.9 & (23.1 to 43.7 ) & 17.2 & (11.4 to 22.7$)$ & 31.3 & (21.8 to 39.1$)$ & 10.5 & (7.0 to 13.8$)$ & 38.0 & (25.0 to 47.1 ) \\
\hline Oceania & 10.2 & (8.1 to 12.5 ) & 9.2 & (6.4 to 12.4$)$ & 10.8 & (8.4 to 13.4 ) & 20.9 & (16.1 to 26.2 ) & 10.7 & (8.3 to 13.0$)$ & 11.6 & (7.8 to 15.7 ) & 10.0 & (7.7 to 12.1$)$ & 24.5 & (18.1 to 30.5$)$ \\
\hline Sub-Saharan Africa, Central & 6.9 & (4.0 to 12.0 ) & 6.0 & (2.6 to 14.3 ) & 9.5 & (7.4 to 11.7 ) & 16.2 & (8.7 to 30.7 ) & 7.1 & (4.6 to 11.0 ) & 6.3 & (3.1 to 13.0 ) & 9.3 & (7.3 to 11.4 ) & 16.7 & (9.9 to 28.7 ) \\
\hline Sub-Saharan Africa, East & 9.4 & (6.2 to 13.1 ) & 9.6 & (5.4 to 15.0 ) & 9.4 & (7.8 to 11.0 ) & 24.2 & (15.9 to 32.0$)$ & 12.0 & (9.0 to 14.4 ) & 13.1 & (8.8 to 16.2 ) & 9.6 & (8.0 to 11.4 ) & 29.7 & (22.8 to 33.9 ) \\
\hline Sub-Saharan Africa, Southern & 9.6 & (7.2 to 11.8 ) & 14.7 & (11.3 to 18.2$)$ & 8.0 & (5.9 to 10.2 ) & 31.0 & (24.5 to 37.1 ) & 10.7 & (8.4 to 13.1$)$ & 17.6 & (13.8 to 21.7$)$ & 8.8 & (6.5 to 11.0$)$ & 34.9 & (28.0 to 41.3 ) \\
\hline Sub-Saharan Africa, West & 5.1 & (3.3 to 9.1 ) & 4.1 & (2.6 to 8.7 ) & 10.9 & (8.9 to 13.0 ) & 13.9 & (9.8 to 23.1 ) & 6.7 & (5.1 to 9.0 ) & 5.7 & (4.1 to 8.4 ) & 10.8 & (9.0 to 12.6$)$ & 18.3 & (14.0 to 23.7$)$ \\
\hline Global & 12.1 & (11.1 to 13.2$)$ & 12.7 & (11.3 to 14.7$)$ & 11.5 & (10.3 to 12.8 ) & 29.6 & (27.4 to 32.0 ) & 14.8 & (13.4 to 16.0$)$ & 17.3 & (15.4 to 19.1$)$ & 12.7 & (11.4 to 13.9$)$ & 34.7 & (32.2 to 37.1 ) \\
\hline
\end{tabular}

Values with $95 \% \mathrm{Cl}$ represent low bone mineral density burden expressed as the percentage of falls-related burden. All ages, both sexes.

DALYs, disability-adjusted life years; YLDs, years lived with disability; GBD, global burden of disease; YLLs, years of life lost due to premature mortality. 
analysis focuses on modifiable risk factors. The TMRED should be possible at the population level and supported by convincing epidemiological evidence of a continuous risk reduction to that exposure distribution. ${ }^{16}$ Longitudinal studies ${ }^{5152}$ have demonstrated that a small percentage of older people can maintain their bone mass over time in the absence of risk factors for osteoporosis. However, the extent to which the differences in BMD observed by age and sex are modifiable is not certain. Men have a higher BMD than women, women show faster rates of bone loss after menopause than men, ${ }^{52-54}$ and there is no definitive evidence that individuals can maintain their young peak bone mass as they age. There is also a significant genetic component to the ability to retain bone mass. ${ }^{55}$ On the basis of this evidence, we used a TMRED that was age- and sexspecific. In order to enable worldwide comparisons, an international reference standard is recommended, ${ }^{57}$ and the choice of an American reference (NHANES III) might lead to overestimates or underestimates of the risk depending on the world region. However, NHANES III is the reference used in the meta-analysis from which we derived the risk relationship between BMD and fractures. ${ }^{11}$ Further research into the modifiability of BMD would help to inform the choice of TMRED.

Separating deaths due to specific fractures from overall deaths due to falls was not straightforward. Osteoporotic fractures are defined as those occurring as the result of a low-impact trauma, but hospital data on falls-related deaths did not include the nature of the injury. Our review did not find prospective population studies with data on mortality due to falls-related fractures covering both sexes and all ages over 50 years. Most of the studies reporting deaths from falls-related fractures were carried out retrospectively from medical charts and death certificates, or they were restricted to frail older populations. This made it difficult to determine what percentage of all falls in a population leads to a fracture-related death.

Hip fracture and clinical vertebral fractures have been shown to be the first and second most important sites, respectively, for osteoporotic fracture-related deaths. 5859 For our mortality analysis, we used in-hospital data, and other fracture types were excluded, as they were less likely to be the underlying cause of death. However, this may have contributed to underestimation of the mortality burden given the evidence that other osteoporotic fracture sites are related to a higher risk of long-term mortality compared with age- and sex-matched peers. ${ }^{5} 6061$ A prospective population-based study conducted over an 18-year period in Australia $^{5}$ showed that the fall-fracture event was likely to be missed out as an underlying cause for some deaths that occurred a long time after the fall, particularly in non-hip and non-vertebral fractures. However, long-term mortality after fractures is tedious to interpret within the scope of the GBD Study. Previous studies have demonstrated that mortality is highly related to baseline frailty, ${ }^{62-65}$ and it is hard to estimate what percentage of the excess mortality is really due to the fracture event.

As the exposure variable-measuring method, DXA is considerably more expensive and technically more complicated than measurement systems for other risk factors such as hypertension or body mass index. Consequently, the availability of DXA scans is limited, ${ }^{66}$ leading to a possible selection bias towards countries with better access to DXA scans. Selecting the FN as the location of the fracture further restricted the number of papers that could be included. Furthermore, the application of standardisation equations among different DXA manufacturers ${ }^{28}$ is unlikely to have removed all differences, especially between models from the same manufacturer. ${ }^{67} 68$ In addition, BMD has low sensitivity in identifying fracture risk, ${ }^{69}$ being purely a quantitative value that does not account for other mechanical properties known to influence bone strength, and consequently leading to an underestimation of the burden associated with osteoporosis.

Another important limitation is selection bias in the source studies. Most of the studies excluded subjects with a history of fracture, bone metabolism diseases, or receiving treatments that might affect bone metabolism. We expected to find discrepancies in the BMD values among different study groups depending on the exclusion or inclusion of such subjects, but linear regression models failed to prove this assumption. The reasons for this are not fully apparent, but it might be related to the heterogeneity among studies. We recommend including patients with previous fractures or a diagnosed bone disease in similar future studies. This is particularly important in elderly populations, as the percentage of individuals with a history of previous fragility fractures is high and excluding such subjects makes the sample not truly representative of the real population and underestimates the real risk.

\section{CONCLUSION}

This analysis demonstrates that low BMD is a growing global health burden. However, this is likely to reflect only a small part of the true burden of osteoporosis, given that BMD cannot reflect other important components of bone strength. For future studies of GBD, we strongly recommend a focus on osteoporosis as a disease rather than a risk factor. Health information systems should be better equipped to detect fragility fractures and longterm mortality related to them. The information provided could be used to better inform targeted clinical and public health prevention and management programmes.

\section{Author affiliations}

${ }^{1}$ Northern Clinical School, Institute of Bone and Joint Research, University of Sydney, St Leonards, New South Wales, Australia

${ }^{2}$ Institut d'Investigació Biomèdica de Bellvitge, Hospital Universitari de Bellvitge, Departament de Reumatologia, L'Hospitalet de Llobregat, Barcelona, Spain ${ }^{3}$ Institute for Health Metrics and Evaluation, University of Washington, Seattle, Washington, USA

${ }^{4}$ School of Population Health, University of Queensland, Herston, Queensland, Australia

${ }^{5}$ Queensland Children's Medical Research Institute, University of Queensland, Herston, Queensland, Australia

${ }^{6}$ University of New South Wales, New South Wales, Australia

${ }^{7}$ The George Institute for Global Health, University of Sydney, Sydney, New South Wales, Australia

${ }^{8}$ Centro Universitario del Sur, CUSUR, Universidad de Guadalajara, Guadalajara, Jalisco, Mexico

Correction notice This article has been corrected since it was published Online First.

Acknowledgements We thank Professor Jose Adolfo Rodriguez Portales and Dr Joe Zmuda, who were kind enough to provide us with data upon request, Professor Anthony Woolf for his support and expert opinion, and Professor John A Kanis and the International Osteoporosis Foundation for their feedback on our methodology.

Contributors LSR was the leader for the Osteoporosis Working Group and led the writing of the article. EC, TV, SSL, RN, LV, DH, JMN and LM reviewed the different drafts of the article, sent comments and suggested changes. LSR performed most of the systematic review process and coordinated the extraction data team formed by ES, NW, MM, JSC, YL, NK, JMN, CSH and CK. DH, LSR, TV, LV, RN, JMN and LM developed the Risk of Bias Tool adapted to low bone mineral density as a risk factor in the GBD Study. LSR, LV, RN, EC, TV, LM and SSL developed the estimates of risk-specific exposure, theoretical-minimum-risk exposure distribution, and RR inputs, and checked and interpreted results. TV and SSL were members of the core team for the GBD Study and supervised all the estimates analysis. LM was the MSK Expert Group Leader and led the networking with world experts and supervised the overall work; ES and DH coordinated the Osteoporosis Working Team within the rest of the MSK Expert Group and the GBD Study Group. 
Funding Supported by the Bill and Melinda Gates Foundation (TV, SSL, DH, RN and EC), Australian Commonwealth Department of Health and Ageing (ES and LM), National Health and Medical Research Council of Australia (NHMRC Capacity Building Grant 456002 to LV, Postgraduate Scholarship 569772 to DH), Sociedad Española de Reumatología (Beca FER 2009\&2010 to LSR), University of Sydney (Student Research Scholarship to NK), Institute of Bone and Joint Research\&University of Sydney (ES, NW, JSC, MM, LSR, CK and DH).

\section{Competing interests None.}

Provenance and peer review Not commissioned; externally peer reviewed.

Data sharing statement The team are happy to provide additional data upon request.

\section{REFERENCES}

1 NIH Consensus Development Panel on Osteoporosis Prevention, Diagnosis, and Therapy. Osteoporosis prevention, diagnosis, and therapy. JAMA 2001;285:785-95

2 Bertram M, Norman $R$, Kemp L, et al. Review of the long-term disability associated with hip fractures. Inj Prev 2011;17:365-70.

3 Naves Diaz M, Diaz Lopez JB, Rodriguez Rebollar A, et al. Effect of vertebral fracture on health related quality of life in a Spanish population older than 54 years. Med Clin (Barc) 2001;116:533-5.

4 Kaukonen JP, Karaharju EO, Porras $\mathrm{M}$, et al. Functional recovery after fractures of the distal forearm. Analysis of radiographic and other factors affecting the outcome. Ann Chir Gynaecol 1988;77:27-31.

5 Bliuc $D$, Nguyen ND, Milch VE, et al. Mortality risk associated with low-trauma osteoporotic fracture and subsequent fracture in men and women. JAMA 2009;301:513-21.

6 Kanis JA, Oden A, Johnell 0, et al. Excess mortality after hospitalisation for vertebral fracture. Osteoporos Int 2004;15:108-12.

7 Johnell 0 , Kanis JA. An estimate of the worldwide prevalence, mortality and disability associated with hip fracture. Osteoporos Int 2004;15:897-902.

8 Johnell 0 , Kanis JA. An estimate of the worldwide prevalence and disability associated with osteoporotic fractures. Osteoporos Int 2006;17:1726-33.

9 Sanders KM, Nicholson GC, Ugoni AM, et al. Health burden of hip and other fractures in Australia beyond 2000. Projections based on the Geelong Osteoporosis Study. Med J Aust 1999;170:467-70.

10 Marshall $\mathrm{D}$, Johnell $\mathrm{O}$, Wedel $\mathrm{H}$. Meta-analysis of how well measures of bone mineral density predict occurrence of osteoporotic fractures. BMJ 1996;312:1254-9.

11 Johnell 0 , Kanis JA, Oden A, et al. Predictive value of BMD for hip and other fractures. J Bone Miner Res 2005;20:1185-94.

12 WHO Study Group. Assessment of fracture risk and its application to screening for postmenopausal osteoporosis. Geneva, Switzerland: World Health Organization, 1994.

13 Official positions. The International Society for Clinical Densitometry. 2007. http:// www.iscd.org.

14 Lim SS, Vos T, Flaxman AD, et al. A comparative risk assessment of burden of disease and injury attributable to 67 risk factors and risk factor clusters in 21 regions, 1990-2010: a systematic analysis for the Global Burden of Disease Study 2010. Lancet 2012:380:2224-60.

15 Murray CJ, Vos T, Lozano R, et al. Disability-adjusted life years (DALYS) for 291 diseases and injuries in 21 regions, 1990-2010: a systematic analysis for the Global Burden of Disease Study 2010. Lancet 2012;380:2197-223.

16 The GBD Study 2010. http://www.globalburden.org.

17 Vos T, Flaxman AD, Naghavi M, et al. Years lived with disability (YLDs) for 1160 sequelae of 289 diseases and injuries 1990-2010: a systematic analysis for the Global Burden of Disease Study 2010. Lancet 2012;380:2163-96.

18 Salomon JA, Vos T, Hogan DR, et al. Common values in assessing health outcomes from disease and injury: disability weights measurement study for the Global Burden of Disease Study 2010. Lancet 2012;380:2129-43.

19 Hoy D, Smith E, Cross M, et al. The global burden of musculoskeletal conditions for 2010: an overview of methods. Ann Rheum Dis 2014;73:982-9.

20 Cross M, Smith E, Hoy D, et al. The global burden of hip and knee osteoarthritis: estimates from the Global Burden of Disease 2010 study. Ann Rheum Dis 2014;73:1323-30.

21 Cross M, Smith E, Hoy D, et al. The global burden of rheumatoid arthritis: estimates from the Global Burden of Disease 2010 study. Ann Rheum Dis 2014;73:1316-22.

22 Smith E, Hoy D, Cross M, et al. The global burden of gout: estimates from the Global Burden of Disease 2010 study. Ann Rheum Dis 2014;73:1470-6.

23 Hoy $D$, March L, Brooks $P$, et al. The global burden of low back pain: estimates from the Global Burden of Disease 2010 study. Ann Rheum Dis 2014;73:968-74.

24 Hoy D, March L, Woolf A, et al. The global burden of neck pain: estimates from the Global Burden of Disease 2010 study. Ann Rheum Dis 2014;73:1309-15.

25 Driscoll T, Jacklyn G, Orchard J, et al. The global burden of occupationally-related low back pain: estimates from the Global Burden of Disease 2010 study. Ann Rheum Dis 2014;73:975-81.

26 Smith E, Hoy D, Cross M, et al. The global burden of other musculoskeletal disorders: estimates from the Global Burden of Disease 2010 study. Ann Rheum Dis 2014;73:1462-9.
27 Hoy D, Smith E, Blyth F, et al. Reflecting on the global burden of musculoskeletal conditions: lessons learnt, next steps. Ann Rheum Dis 2014; in press.

28 Lu Y, Fuerst T, Hui S, et al. Standardization of bone mineral density at femoral neck, trochanter and Ward's triangle. Osteoporos Int 2001;12:438-44.

29 Hoy $\mathrm{D}$, Brooks $\mathrm{P}$, Woolf $\mathrm{A}$, et al. Assessing risk of bias in prevalence studies: modification of an existing tool and evidence of interrater agreement. J Clin Epidemiol 2012;65:934-9.

30 Sanchez-Riera L, Wilson N, Hoy D, et al. Use of a quality assessment tool for a systematic review on osteoporosis prevalence. Osteoporos Int 2010;21(Suppl 1): S276.

31 Abrahamsen B, Vestergaard P, Rud B, et al. Ten-year absolute risk of osteoporotic fractures according to BMD T score at menopause: the Danish Osteoporosis Prevention Study. J Bone Miner Res 2006;21:796-800

32 Hartl F, Tyndall A, Kraenzlin $\mathrm{M}$, et al. Discriminatory ability of quantitative ultrasound parameters and bone mineral density in a population-based sample of postmenopausal women with vertebral fractures: results of the Basel Osteoporosis Study. J Bone Miner Res 2002;17:321-30.

33 Kung AW, Lee KK, Ho AY, et al. Ten-year risk of osteoporotic fractures in postmenopausal Chinese women according to clinical risk factors and BMD T-scores: a prospective study. J Bone Miner Res 2007;22:1080-7.

34 Lopes JB, Danilevicius CF, Takayama $L$, et al. Prevalence and risk factors of radiographic vertebral fracture in Brazilian community-dwelling elderly. Osteoporos Int 2011:22:711-19.

35 McLean RR, Jacques PF, Selhub J, et al. Plasma B vitamins, homocysteine, and their relation with bone loss and hip fracture in elderly men and women. I Clin Endocrinol Metab 2008:93:2206-12.

36 Blaizot S, Delmas PD, Marchand F, et al. Risk factors for peripheral fractures vary by age in older men-the prospective MINOS study. Osteoporos Int 2011;22:1755-64.

37 Jacobs JW, Da Silva JA, Armbrecht G, et al. Prediction of vertebral fractures is specific for gender and site of bone mineral density measurement. J Rheumatol 2010;37:149-54.

38 Cauley JA, Lui LY, Ensrud KE, et al. Bone mineral density and the risk of incident nonspinal fractures in black and white women. JAMA 2005;293:2102-8.

39 Ezzati M, Hoorn SV, Lopez AD, et al. Comparative Quantification of Mortality and Burden of Disease Attributable to Selected Risk Factors 2006

40 Ezzati M, Hoorn SV, Lopez AD, et al. Comparative quantification of mortality and burden of disease attributable to selected risk factors. Source: global burden of disease and risk factors. Washington, DC: World Bank, 2006. Chapter 4, pp 241-68.

41 Looker AC, Wahner HW, Dunn WL, et al. Updated data on proximal femur bone mineral levels of US adults. Osteoporos Int 1998;8:468-86.

42 Barendregt JJ, Veerman JL. Categorical versus continuous risk factors and the calculation of potential impact fractions. J Epidemiol Community Health 2010;64:209-12.

43 Ministry of Health (Brazil). Brazil Hospital Information System 2006-2009.

44 Canadian Institute for Health Information (CIHI). Canada Discharge Abstract Database 1994-2009.

45 Ministry of Health (Mexico). Mexico Ministry of Health Hospital Discharges 20002009.

46 Healthcare Cost and Utilization Project (HCUP), Agency for Healthcare Research and Quality (AHRQ). United States State Inpatient Databases 2003-2008.

47 National Center for Health Statistics (NCHS), Centers for Disease Control and Prevention (CDC), US Census Bureau. United States National Hospital Discharge Survey 19792009.

48 http://www.abs.gov.au/AUSSTATS/abs@.nsf/Lookup/3303.0Main+Features12003? OpenDocument

49 Sanchez-Riera L, Wilson N, Kamalaraj N, et al. Osteoporosis and fragility fractures. Best Pract Res Clin Rheumatol 2010;24:793-810.

50 Kanis JA, Johnell O, Odén A, et al. Ten year probabilities of osteoporotic fractures according to BMD and diagnostic thresholds. Osteoporos Int 2001;12: 989-95.

51 Cauley JA, Lui LY, Barnes D, et al. Successful skeletal aging: a marker of low fracture risk and longevity. The Study of Osteoporotic Fractures (SOF). J Bone Miner Res 2009:24:134-43.

52 Burger $\mathrm{H}$, de Laet $\mathrm{CE}$, van Daele PL, et al. Risk factors for increased bone loss in an elderly population: the Rotterdam Study. Am J Epidemiol 1998;147:871-9.

53 Yoshimura N, Kinoshita H, Danjoh S, et al. Bone loss at the lumbar spine and the proximal femur in a rural Japanese community, 1990-2000: the Miyama study. Osteoporos Int 2002;13:803-8.

54 Jones G, Nguyen T, Sambrook P, et al. Progressive loss of bone in the femoral neck in elderly people: longitudinal findings from the Dubbo osteoporosis epidemiology study. BMJ 1994;309:691-5.

55 Arden NK, Spector TD. Genetic influences on muscle strength, lean body mass, and bone mineral density: a twin study. J Bone Miner Res 1997;12:2076-81.

56 Harris M, Nguyen TV, Howard GM, et al. Genetic and environmental correlations between bone formation and bone mineral density: a twin study. Bone 1998;22: $141-5$. 
57 Kanis JA, McCloskey EV, Johansson $\mathrm{H}$, et al. A reference standard for the description of osteoporosis. Bone 2008;42:467-75.

58 Ioannidis G, Papaioannou A, Hopman WM, et al. Relation between fractures and mortality: results from the Canadian Multicentre Osteoporosis Study. CMAJ 2009;181:265-71.

59 Browner WS, Pressman AR, Nevitt MC, et al. Mortality following fractures in older women. The study of osteoporotic fractures. Arch Intern Med 1996;156: $1521-5$.

60 Morin S, Lix LM, Azimaee M, et al. Mortality rates after incident non-traumatic fractures in older men and women. Osteoporos Int 2011;22:2439-48.

61 Melton L III, Achenbach SJ, Atkinson EJ, et al. Long-term mortality following fractures at different skeletal sites: a population-based cohort study. Osteoporos Int 2013;24:1689-96.

62 Patel KV, Brennan KL, Brennan ML, et al. Association of a modified frailty index with mortality after femoral neck fracture in patients aged 60 years and older. Clin Orthop Relat Res 2014;472:1010-17.
63 Ensrud KE, Ewing SK, Taylor BC, et al. Frailty and risk of falls, fracture, and mortality in older women: the study of osteoporotic fractures. J Gerontol A Biol Sci Med Sci 2007:62:744-51.

64 Cawthon PM, Marshall LM, Michael Y, et al. Frailty in older men: prevalence, progression, and relationship with mortality. J Am Geriatr Soc 2007:55:1216-23.

65 Tosteson AN, Gottlieb DJ, Radley DC, et al. Excess mortality following hip fracture: the role of underlying health status. Osteoporos Int 2007;18:1463-72.

66 International Osteoporosis Foundation. Osteoporosis in the European Union in 2008. 10 years of progress and on-going challenges. 2008. http:// wwwiofbonehealthorg/publications/eu-policy-report-of-2008htm

67 Barthe N, Braillon P, Ducassou D, et al. Comparison of two Hologic DXA systems (QDR 1000 and QDR 4500/A). Br J Radiol 1997:70:728-39.

68 Henzell S, Dhaliwal SS, Price RI, et al. Comparison of pencil-beam and fan-beam DXA systems. J Clin Densitom 2003:6:205-10.

69 Siris ES, Chen YT, Abbott TA, et al. Bone mineral density thresholds for pharmacological intervention to prevent fractures. Arch Intern Med 2004;164:1108-12. 